\title{
O PAPEL DA ENFERMAGEM NA ASSISTÊNCIA AO NEONATO COM MICROCEFALIA POR ZIKA: UMA REVISÃO DE LITERATURA
}

Ligia de Paula Barros Queiroz Especialista em Pediatria e Neonatal pela Faculdade Israelita de Ensino e Pesquisa Albert Einstein, RJ, Brasil queirozligia70@gmail.com

Jackeline Nogueira de Paula Barros Mestre em Clínica Odontológica pela Universidade Federal do Rio de Janeiro (UFRJ), RJ, Brasil jackelinenpb@gmail.com

Catarina Luiza dos Santos José Monteiro Cirurgiã-dentista pela Faculdade do Grande Rio - Unigranrio, RJ, Brasil Catarinamonteiro2310@gmail.com

Igor Torres Resende Graduando em Odontologia pela Faculdade Estácio de Sá - Campus Recreio, RJ, Brasil igortorresresende@gmail.com

\section{RESUMO}

A microcefalia é uma condição neurológica rara devido ao crescimento anormal do cérebro dentro da caixa craniana, geralmente pela fusão prematura dos ossos do crânio. Pode ser causada por fatores genéticos e ambientais, sendo a infecção pelo vírus Zika uma dessas causas. Considerada um problema de saúde pública mundial, com alto impacto na qualidade de vida e de elevado custo no tratamento. Assim, o objetivo desse estudo é apresentar, por meio de revisão de literatura narrativa, o papel da enfermagem na assistência ao neonato com microcefalia por Zika, na tentativa de contribuição para: o diagnóstico precoce, abordagem terapêutica mais adequada e elaboração de políticas públicas de prevenção mais eficazes, visando melhorar sobrevida e qualidade de vida dos pacientes.

PALAVRAS-CHAVE: Microcefalia; Zika vírus; Cuidados de Enfermagem.

\section{THE ROLE OF NURSING IN NEONATAL CARE WITH MICROCEPHALY BY ZIKA: A LITERATURE REVIEW}

\begin{abstract}
Microcephaly is a rare neurological condition due to abnormal growth of the brain inside the cranial cavity, usually by the premature fusion of the bones of the skull. It can be caused by genetic and environmental factors, and Zika virus infection is one of these causes. Considered is a global public health problem with a high impact on quality of life and high treatment costs. Thus, the purpose of this study is to present, through a review of the narrative literature, the role of nursing in the care of the neonate with microcephaly by zika, in an attempt to contribute to: early diagnosis, more appropriate therapeutic approach and elaboration of public policies of prevention, aiming to improve survival and quality of life of patients.
\end{abstract}


KEY WORDS: Microcephaly; Zika virus; Nursing care.

\section{INTRODUÇÃO}

A microcefalia é uma condição neurológica rara devido ao crescimento anormal do cérebro dentro da caixa craniana, geralmente pela fusão prematura dos ossos do crânio. Pode decorrer de anomalias congênitas (presente ao nascimento) ou ter origem após o parto, causada por fatores genéticos e ambientais (GARCIA, 2018). Para a Organização Mundial da Saúde (OMS) pode ser definida como recém-nascidos com um perímetro cefálico (PC) inferior a 2 desvios-padrão, ou seja, mais de 2 desvios-padrão abaixo da média para idade gestacional e sexo, sendo a forma mais grave um PC inferior a 3 desvios-padrão, ou seja, mais de 3 desvios-padrão abaixo da média para idade gestacional e sexo (MS, 2019).

Além da microcefalia congênita, uma série de manifestações têm sido notificadas entre bebês expostos ao vírus Zika no útero, podendo se manifestar a qualquer momento, inclusive envolvendo abortos espontâneos e natimortos, e esse espectro de anormalidades congênitas associadas à exposição dos fetos a esse vírus durante a gestação é conhecido como "síndrome congênita do vírus Zika (SCVZ)". Porém é importante reconhecer que o seu risco exato é desconhecido, pois nem todas as mulheres grávidas expostas terão criança com SCVZ. Tal síndrome, ainda é considerada um problema de saúde pública mundial, com alto impacto psicossocial, repercutindo de forma negativa na qualidade de vida de todos os envolvidos e elevado custo no tratamento, sendo na atualidade um desafio para a comunidade científica (RODRIGUES, 2018; GONÇALVES E TENÓRIO, 2018).

Apesar do grande número de trabalhos envolvendo microcefalia pelo vírus Zika, ainda existem alguns questionamentos a respeito do papel da enfermagem na assistência a esses pacientes, especialmente em serviços de centros referenciados, as quais podem ser reconhecidas nas ações preventivas de controle dos vetores do vírus; na vigilância em saúde; no acompanhamento do pré-natal; na assistência ao parto/puerpério; nas primeiras semanas de vida do neonato e no acompanhamento do crescimento e desenvolvimento (CD) dessas crianças.

Assim, o objetivo desse estudo é apresentar, por meio de revisão de literatura narrativa, o papel da enfermagem na assistência ao neonato com microcefalia por Zika, na tentativa de contribuição para: o diagnóstico precoce, abordagem terapêutica mais adequada e elaboração de políticas públicas de prevenção mais eficazes, visando melhorar sobrevida e qualidade de vida dos pacientes, bem como todos os envolvidos. 


\section{DESENVOLVIMENTO}

\subsection{Metodologia}

Para essa revisão de literatura narrativa, foi realizada busca de artigos científicos nas principais bases de dados: PubMed, Lilacs e Scielo, publicados nos últimos dez anos (2009-2019). Os seguintes descritores em língua portuguesa: Microcefalia; Zika vírus; Cuidados de Enfermagem e inglesa: Microcephaly; Zika virus; Nursing care foram empregados.

\subsection{Vírus ZIKA}

A Zika é uma doença de notificação compulsória, causada por uma infecção viral, cujo principal vetor é o mosquito Aedes aegypti, geralmente encontrado em águas paradas, mas também pode ser transmitida através do ato sexual entre a pessoas contaminada e sua parceira, porém a maior preocupação é a associação desse vírus com a microcefalia e outras doenças neurológicas como a síndrome de Guillain-Barré (NUNEZ et al., 2016).

Segundo a OMS, em 2018, um total de 31.587 casos suspeitos, prováveis e confirmados de doença por ZIKV foram relatados na região das Americas. Destes, 3.473 (11\%) foram confirmados em laboratório. Já no Brasil registrou-se cerca de 19.020 casos, representando $60 \%$ de todos os casos notificados na região, dos quais $7 \%$ foram confirmados laboratorialmente.

Seus sintomas, na maioria dos casos são assintomáticos, mas podem apresentar febre, erupções cutâneas, dor nas articulações (artralgia) e olhos vermelhos (hiperemia conjuntival), dores musculares (mialgia), atrás dos olhos, de cabeça (cefaleia), e menos frequente, edema odinofagia, tosse seca e alterações gastrointestinais, principalmente vômito, além da suspeita de causar má formação fetal. Formas graves e atípicas são raras, mas, quando ocorrem, podem excepcionalmente evoluir para óbito. Porém sua evolução geralmente é leve, entre 2 a 7 dias depois da picada (OMS, 2017).

Os testes de diagnósticos são limitados, contudo as análises da sequência genética do Vírus Zika têm sido importantes para esclarecer os padrões de disseminação global. Foram identificadas duas principais linhagens, conhecidas como linhagens asiáticas e africanas, porém seu potencial epidêmico e sua patogenicidade ainda não são totalmente compreendidas (METSKY et al., 2017; OMS,2019). 
O tratamento recomendado para os casos sintomáticos de infecção pelo vírus Zika é baseado no uso de acetaminofeno (paracetamol) ou dipirona para o controle da febre e da dor. No caso de erupções pruriginosas, anti-histamínico pode ser prescrito. Contudo a prevenção sempre se mostra o melhor caminho e baseia-se em medidas como saneamento básico, uso de repelentes, roupas apropriadas, extinção de criadouros do mosquito, uso de preservativos caso desconfie que seu parceiro foi infectado, evitar ir para locais com vírus Zika, educação em saúde, entre outras, como vacinas, porém alguns estudos chamam a atenção para o uso residual de inseticidas (WERMELINGER, 2018; CORONEL et al., 2019).

\subsection{Microcefalia}

Pode referir-se a uma síndrome congênita causada pelo vírus Zika em que a circunferência da cabeça é menor que o normal em relação ao sexo e idade da criança com consequências neurológicas e motoras, impactando de forma negativa na qualidade de vida de todos os envolvidos.

Segundo o Ministério da Saúde (MS), dentre os 17.041, entre novembro de 2015 a dezembro de 2018 , dos casos notificados de suspeitos de alterações no crescimento e desenvolvimento possivelmente relacionadas à infecção pelo vírus Zika e outras etiologias infecciosas, 3.332 (19,6\%) foram confirmados, porém somente 1.739 (60,7\%) crianças estavam recebendo atendimento em puericultura, 1.000 (34,9\%) em estimulação precoce e $1.828(63,8 \%)$ no serviço de atenção especializada. E esta alta prevalência pode ser diferente de acordo com as várias regiões geográficas estudadas, sendo maior na região Nordeste do Brasil (58,5\%).

Os sintomas da microcefalia consistem em epilepsia, dificuldades de visão, audição, fala, e o atraso no desenvolvimento de uma série de habilidades, motoras e cognitivas dependerá da área cerebral afetada. Já o diagnóstico preciso é cada vez mais importante para definição da melhor abordagem terapêutica e deve estar fundamentado em sinais fornecidos pelo exame clínico, laboratorial e de imagens. Baseia-se na medição do perímetro cefálico (PC) e seu registro em gráficos para o crescimento craniano comparando com valores normais de referência, de acordo com sexo e idade. Também é possível diagnosticar durante o pré-natal, porém somente o médico poderá determinar o exame de imagem mais adequado. Ainda, recomenda-se a triagem do líquido amniótico em busca de anormalidades ou infecções congênitas, quando possível, especialmente nos casos onde os testes feitos com mulheres foram negativos para Zika, mas seus ultrassons indicam anormalidades no cérebro do feto (MS,2017). 
Já com relação ao tratamento, não existe um específico e sim um conjunto de ações de suporte, que dependendo da função comprometida, auxiliará no desenvolvimento do bebe e da criança. Tal tratamento é preconizado pelo Sistema Único de saúde (SUS) e deve estar disponível nos serviços de atenção básica, especializados de reabilitação, de exame e diagnóstico e hospitalares. E no intuito de orientar os profissionais de saúde e frente ao aumento de casos de microcefalia em 2015, o Ministério da Saúde (MS) elaborou o "Protocolo de atenção e resposta à ocorrência de microcefalia e/ou alterações do Sistema Nervoso Central (SNC)" e a OMS o Kit de Ferramentas (inclui três manuais) para o atendimento e apoio a pessoas afetadas por complicações associadas ao vírus Zika e este foi desenvolvido para servir como guia modelo, com o objetivo de melhorar a preparação do país para surtos de vírus Zika (MS,2016).

Para o MS, uma questão importante é o aleitamento materno que deve ser mantido e contínuo até os dois anos ou mais, sendo ele exclusivo até os seis primeiros meses de vida da criança, em adição ao estímulo precoce do Recém Nascido (RN), cujo período mais importante vai de 0 a 3 anos de idade e consiste em uma série de aspectos relacionados ao desenvolvimento neuropsicomotor da criança, além do uso de tecnologia assistida (bengala e cadeira de rodas), da importância das brincadeiras e a participação ativa de familiares, com objetivo de maximizar o potencial de cada criança. Porém, outros cuidados como manter o bebe protegido com telas de proteção, roupas compridas e o acompanhamento de rotina na Unidade Básica de Saúde também são preconizados, inclusive o acompanhamento de crianças assintomáticas cujas mães foram expostas à doença por um período de 3 anos (SANTOS et al., 2018).

Diante disso, o governo Brasileiro proporcionou alguns benefícios sociais, através da lei no 13.301, de 27 de junho de 2016, como: auxílio de um salário mínimo garantido pela Previdência Social (Benefício de Prestação Continuada - BPC) por 3 anos e para aquelas mães sob o regime Consolidação das Leis do Trabalho (CLT), ampliação da licença-maternidade de 120 dias para 180 dias, o que é irrisório diante de tal problema, já que estudos mostram que a maioria desses progenitores possuem baixas condições socioeconômicas, além de que a referida doença trará consequências para o resto da vida.

\subsection{Microcefalia e o papel da enfermagem}

Partindo-se do princípio que os profissionais de enfermagem fazem parte da equipe de saúde que presta assistência à criança e estes trabalham em ações e intervenções de promoção, 
prevenção e recuperação à saúde, sua atuação diante desse panorama é de fundamental importância.

Sabe-se que o papel educacional da enfermagem é fundamental e consiste na orientação de famílias com crianças portadoras de microcefalias, principalmente quanto a prevenção e a importância do pré-natal, pois assim a gestante poderá receber o diagnóstico precoce e pronta atenção (PUIG,2018).

Para o MS, 2017 de acordo com as diretrizes do caderno de Orientações Integradas de Vigilância e Atenção à Saúde, cuidados ao neonato portador de microcefalia já se iniciam na sua primeira consulta após o parto/nascimento com a medição imediata do perímetro cefálico (PC) e com a coleta de sangue (triagem infecciosa) caso se confirme o diagnóstico.

A anamnese, exame físico e a triagem neonatal que compreendem: Triagem Auditiva Neonatal (TAN), Triagem Ocular Neonatal (TON), Teste do Pezinho e Teste do Coraçãozinho, segundo recomendações do Manual Técnico da Triagem Neonatal/Biológica do MS, devem ser realizadas, bem como as práticas de atenção ao parto/nascimento do portador de microcefalia, como por exemplo a amamentação na primeira hora de vida .

O enfermeiro ainda pode auxiliar no diagnóstico de forma precoce e adequada na medida em que consegue identificar os sintomas da infecção pelo vírus Zika em gestantes (RODRIGUEZ, 2017), além da detecção de alterações no crescimento, nutrição e desenvolvimento neuropsicomotor da criança, que deve ser avaliada constantemente em consultas nas Unidades Básicas de Saúde (UBS), devido a possibilidade de complicações (DE MEDEIROS et al., 2018).

Monitorar os sinais vitais, realizar ações de controle da infecção e o manejo da dor, bem como providenciar apoio emocional, estabelecendo relação e comunicação entre a família, devem ser estimulados de forma humanizada (BRITO et al., 2018).

Botell e Bermúdez (2016) sugere ainda para todas as gestantes com suspeita de infecção pelo vírus Zika, além de seguir as diretrizes gerais de controle durante a gravidez, a medição do volume do líquido amniótico, a altura uterina (que serve para avaliar se há alterações no crescimento e na morte fetal), avaliação da anatomia e vitalidade fetal.

Para Santos e Barbosa (2019) o profissional de enfermagem ainda deve realizar atividades de estimulação ao recém-nascido, com microcefalia relacionada ao vírus Zika com ênfase nas necessidades da criança e da família, visando minimizar atrasos no crescimento e desenvolvimento.

Sendo assim, capacitação profissional é uma possibilidade para prestar uma assistência de qualidade e humanizada a essas famílias, em que se faz necessário o aperfeiçoamento das 
intervenções com correlações a assistência prestada e com uma constante busca pela qualificação e de novas pesquisas em proposições que abordem essa temática.

\section{CONSIDERAÇÕES FINAIS}

Enfim, acredita-se que esta pesquisa contribuiu com os profissionais da enfermagem, para o conhecimento podendo auxiliar na prevenção e nos cuidados de crianças com microcefalia pelo vírus Zika, melhorando, assim, a assistência de forma sistematizada e com qualidade.

\section{REFERÊNCIAS}

BRASIL et al. Triagem Neonatal Biológica: manual técnico. 2016.

BRASIL. Ministério da Saúde. Secretaria de Atenção à Saúde. Diretrizes de estimulação precoce: crianças de zero a 3 anos com atraso no desenvolvimento neuropsicomotor decorrente de microcefalia / Ministério da Saúde, Secretaria de Atenção à Saúde. Brasília: Ministério da Saúde, 2016c. 123p. Disponível em:

<http://portalarquivos.saude.gov.br/images/pdf/2016/janeiro/13/Diretrizes-de EstimulacaoPrecoce.pdf>. Acesso em: 27 nov. 2019.

Botell, Miguel Lugones, and Marieta Ramírez Bermúdez. 2016. Infecci? N Por Virus Zika En El Embarazo y Microcefalia. Revista Cubana de Obstetricia y Ginecologia, 42(3): 398-411.

BRITO, Ana Paula Moreira et al. Enfermagem no contexto familiar na prevenção de anomalias congênitas: revisão integrativa. Journal of Health \& Biological Sciences, v. 7, n. 1 (Jan-Mar), p. 6474, 2018.

CORONEL, Diana et al. Pregnancy surveillance and Zika disease: a surveillance methodology proposal for a Zika vaccine efficacy trial. Revista Latinoamericana de Infectología Pediátrica, v. 32, n. 2, p. 61-68, 2019.

DE MEDEIROS, Valéria Alves Barros et al. Assistência de Enfermagem ao Neonato com Microcefalia. Caderno de Graduação-Ciências Biológicas e da Saúde-UNIT-ALAGOAS, v. 4, n. 3, p. 67, 2018.

GARCIA, Leila Posenato. Epidemia do vírus Zika e microcefalia no Brasil: emergência, evolução e enfrentamento. Texto para Discussão, 2018.

GONÇALVES, Amanda Estrela; TENÓRIO, Sibele Dayane Brazil; DA SILVA FERRAZ, Priscila Correia. Aspectos socioeconômicos dos genitores de crianças com microcefalia relacionada ao Zika vírus. Revista Pesquisa em Fisioterapia, v. 8, n. 2, p. 155-166, 2018.

Metsky $\mathrm{HC}$, Matranga $\mathrm{CB}$, Wohl S, et al. Zika virus evolution and spread in the Americas. Nature, 546(7658):411-415, 2017. 
Ministério da Saúde (BR). Secretaria de Atenção à Saúde. Protocolo de atenção à saúde e resposta à ocorrência de microcefalia [recurso eletrônico] / Ministério da Saúde, Secretaria de Atenção à Saúde. - Brasília: Ministério da Saúde, 2016. 42 p : il.

Ministério da Saúde (BR). Secretaria de Vigilância em Saúde. Boletim Epidemiológico Monitoramento integrado de alterações no crescimento e desenvolvimento relacionadas à infecção pelo vírus Zika e outras etiologias infecciosas, até a Semana Epidemiológica 52 de 2018. Sistema de Informações sobre Nascidos Vivos (Sinasc); Registro de Eventos em Saúde Pública (RESPMicrocefalia). 2019; 50(8):1-8.

Ministério da Saúde (BR). Secretaria de Vigilância em Saúde (SVS) Secretaria de Atenção à Saúde (SAS). Orientações integradas de vigilância e atenção à saúde no âmbito da Emergência de Saúde Pública de Importância Nacional: procedimentos para o monitoramento das alterações no crescimento e desenvolvimento a partir da gestação até a primeira infância, relacionadas à infecção pelo vírus Zika e outras etiologias infecciosas dentro da capacidade operacional do SUS. SVS/SAS. 2017; 1(1):5-158.

Ministério da Saúde (BR). Secretaria de Vigilância em Saúde. Vírus Zika no Brasil: A resposta do SUS. MS (recurso eletrônico). Brasília; 2017.

Ministério da Saúde (BR). Secretaria de Atenção à Saúde. Departamento de Atenção Especializada e Temática. Triagem Neonatal Biológica. Manual Técnico. 2016; 1(1):5-75.

Ministério da Saúde (BR). Secretaria de Atenção à Saúde. Diretrizes de estimulação precoce: crianças de zero a 3 anos com atraso no desenvolvimento neuropsicomotor. Brasília; 2016.

Ministério da Saúde (BR). Sistema Universidade Aberta do SUS/Fundação Oswaldo Cruz \& Centro de Telessaúde HC-UFMG \& Centro Universitário Newton Paiva. Estimulação Precoce a Criança Com Microcefalia De 0 A 3 Anos. SE/UMA - SUS. Brasília; 2017.

Ministério da Saúde (BR). Microcefalia: causas, sintomas, tratamento e prevenção. Disponível em: $<$ http://www.saude.gov.br/saude-de-a-z/microcefalia>.

Nuñez,E; Vasquez, M; Beltran L, Briana y Padgett, Denis. Virus Zika en Centroamérica y sus complicaciones. Acta méd. peruana [online]. 2016, vol.33, n.1 [citado 13/04/2019], pp.42-49. Disponivel em:

<http://www.scielo.org.pe/scielo.php?script=sci_arttext\&pid=S172859172016000100008\&lng=es \&nrm=iso>. ISSN 1728-5917.)

Puig, Solano. "Intervención de Enfermería Durante La Aparición Del Zika En San Miguelito, Camagüey." 2018.

OMS. ATUALIZAÇÀO EPIDEMIOLOGICA DO ZIKA. Disponível em: https://www.who.int/emergencies/diseases/zika/epidemiology-update/en/. Acesso em: 2 de julho de 2019.

OMS. MICROCEFALIA. Disponível em: https://www.who.int/news-room/factsheets/detail/microcephaly. Acesso em: 16 de fevereiro de 2018. 
World Health Organization. Countries and territories with current or previous Zika virus transmission. Updated July 2019. Accessible at: https://www.who.int/emergencies/diseases/zika/countries-with-zika-and-vectors-table.pdf

OPAS/OMS Brasil - Perguntas e respostas sobre o vírus Zika e suas consequências. Disponível em: $<$ https://www.paho.org/bra/index.php?option=com content\&view=article\&id=5292:perguntas-erespostas-sobre-o-virus-zika-e-suas-consequencias\&Itemid=882>. Acesso em: 26 de nov. 2019

RODRIGUES, Fabiana Passos. MICROCEFALIA, IMPACTOS SOCIAIS E EMOCIONAIS: CAMPOS DE ATUAÇÃO E DESAFIOS DO PROFISSIONAL PSICÓLOGO. Revista Científica UMC, v. 3, n. 3, 2018.

Rodríguez Fonseca, María Fernanda. 2017. "Infección Por Virus Del Zika En El Embarazo.Revisión y Plan de Cuidados de Enfermería." Repositorio Documental UVa 1. http://uvadoc.uva.es/handle/10324/24455.

SANTOS, LEIDIANE SILVA et al. A participação da família no trabalho de reabilitação da criança com microcefalia. Caderno de Graduação-Ciências Biológicas e da Saúde-UNIT-ALAGOAS, v. 4, n. 2, p. 189, 2018.

SANTOS, José Roberto Bispo; BARBOSA, João de Sousa Pinheiro. ASSISTÊNCIA DO ENFERMEIRO AO NEONATO PORTADOR DE MICROCEFALIA: VÍRUS ZIKA. ReBIS-Revista Brasileira Interdisciplinar de Saúde, v. 1, n. 3, 2019.

WERMELINGER, Eduardo Dias. Borrifar inseticidas de efeito residual para mitigar o risco da microcefalia causada pela zika. Physis: Revista de Saúde Coletiva, v. 28, p. e280303, 2018. 